\title{
Potato consumption and risk of pancreatic cancer in the HELGA cohort
}

\author{
Lene A. Åsli ${ }^{1 *}$, Tonje Braaten ${ }^{1}$, Anja Olsen ${ }^{2}$, Anne Tjønneland $^{2}$, Kim Overvad $^{3}$, Lena Maria Nilsson ${ }^{4,5}$, \\ Frida Renström $^{6,7}$, Eiliv Lund ${ }^{1}$ and Guri Skeie ${ }^{1}$ \\ ${ }^{1}$ Department of Community Medicine, University of Tromsø - The Arctic University of Norway, N-9037 Tromsø, Norway \\ ${ }^{2}$ Danish Cancer Society Research Center, Strandboulevarden 49, 2100 Copenhagen, Denmark \\ ${ }^{3}$ Department of Public Health, Section for Epidemiology, Bartbolins Alle 2, 8000 Aarhus C, Denmark \\ ${ }^{4}$ Arctic Research Centre at Umeå University (Arcum), 90187 Umeå, Sweden \\ ${ }^{5}$ Public Health and Clinical Medicine, Nutritional Research, Umeå University, 90185 Umeå, Sweden \\ ${ }^{6}$ Department of Biobank Research, Umeå University, 90187 Umeå, Sweden \\ ${ }^{7}$ Department of Clinical Sciences, Lund University, 221 OO Lund, Sweden
}

(Submitted 17 March 2017 - Final revision received 17 September 2017 - Accepted 5 March 2018)

\section{Abstract}

Potatoes have been a staple food in many countries throughout the years. Potatoes have a high glycaemic index (GI) score, and high GI has been associated with several chronic diseases and cancers. Still, the research on potatoes and health is scarce and contradictive, and we identified no prospective studies that had investigated the association between potatoes as a single food and the risk of pancreatic cancer. The aim of this study was to prospectively investigate the association between potato consumption and pancreatic cancer among 114240 men and women in the prospective HELGA cohort, using Cox proportional hazard models. Information on diet (validated FFQ's), lifestyle and health was collected by means of a questionnaire, and 221 pancreatic cancer cases were identified through cancer registries. The mean follow-up time was $11.4(95 \%$ CI $0.3,16.9)$ years. High consumption of potatoes showed a non-significantly higher risk of pancreatic cancer in the adjusted model (hazard ratio (HR) 1.44; $95 \%$ CI $0.93,2 \cdot 22, P_{\text {for trend }} 0.030$ ) when comparing the highest $v$. the lowest quartile of potato consumption. In the sex-specific analyses, significant associations were found for females (HR $2 \cdot 00 ; 95 \%$ CI 1.07, 3.72, $P_{\text {for trend }} 0 \cdot 020$ ), but not for males (HR 1.01; $95 \%$ CI 0.56, 1.84, $P_{\text {for trend }} 0.34$ ). In addition, we explored the associations by spline regression, and the absence of dose-response effects was confirmed. In this study, high potato consumption was not consistently associated with a higher risk of pancreatic cancer. Further studies with larger populations are needed to explore the possible sex difference.

\section{Key words: Cohort studies: Epidemiology: Potatoes: Cancer}

Pancreatic cancer is the eighth most common cause of cancer death worldwide, and 227000 individuals were diagnosed with pancreatic cancer in $2008^{(1)}$. In the Nordic countries, pancreatic cancer contributes to $2.4 \%$ of the cancer cases in men and $2.7 \%$ of the cancer cases in women ${ }^{(2)}$. Pancreatic cancer is hard to detect early ${ }^{(3)}$, and the cancer is generally advanced, and usually fatal, by the time it is diagnosed ${ }^{(4)}$. The 5 -year prevalence of people living with pancreatic cancer worldwide is estimated to be $4 \cdot 1$ per $100000^{(3)}$. There is limited evidence suggesting consumption of red and processed meat, foods and beverages containing fructose and heavy alcohol drinking (more than 3 drinks/d) as risk factors of pancreatic cancer. The evidence for fruits and physical activity is too limited and inconsistent to draw any conclusion ${ }^{(5)}$. Other non-dietary risk factors for pancreatic cancer are more established.
Approximately $25 \%$ of cases of pancreatic cancer are attributable to tobacco smoking ${ }^{(5)}$, and the risk also increases with age. Factors such as body fatness and greater childhood growth have been identified as, respectively, convincing and probable causes of pancreatic cancer ${ }^{(5)}$. Chronic pancreatitis, insulin resistance, type 2 diabetes $^{(4,5)}$ and infection with Helicobacter pylori have also been identified as risk factors of this cancer ${ }^{(4)}$. In addition, pancreatic cancer seems to run in some families, and some of these are caused by an inherited syndrome ${ }^{(6)}$. About $10 \%$ of the pancreatic cancer cases are owing to genetic changes, indicating that most people who are diagnosed with pancreatic cancer do not have a family history of it. Potatoes are the fourth most plentiful food crop in the world after wheat, rice and maize ${ }^{(7)}$, and are a good source of fibre, carbohydrates (starches), niacin, folate, vitamin $\mathrm{C}$ and minerals (e.g. $\mathrm{K}, \mathrm{Mg}$

Disclaimer: Some of the data in this article are from the Cancer Registry of Norway. The Cancer Registry of Norway is not responsible for the analysis or interpretation of the data presented.

Abbreviations: GI, glycaemic index; HR, hazard ratio.

* Corresponding author: L. A. Åsli, fax +47 776448 31, email lene.a.asli@uit.no 
and $\mathrm{Fe})^{(8,9)}$. According to World Cancer Research Fund/American Institute of Cancer Research report (WCRF/AICR), the evidence for associations between folate, vitamin C, carbohydrates and pancreatic cancer risk is weak or inconclusive ${ }^{(5)}$. Generally, the research on health effects of potato consumption is limited and contradictory, especially regarding the long-term health effects of potato in diets worldwide ${ }^{(10,11)}$. Yet, some studies have found a high potato consumption to be associated with higher risk of pancreatic cancer $^{(12)}$, colon cancer (tendency) $^{(13)}$ and colorectal cancer ${ }^{(14)}$. Other studies have found associations between high potato consumption and risk of gastric cancer among women but not among men ${ }^{(15)}$, and risk of rectal cancer among Whites but not among AfricanAmericans ${ }^{(16)}$. An association between potato consumption and risk of oral and pharyngeal cancer has also been observed ${ }^{(17)}$. On the other hand, some short-term studies have implicated that potatoes contain anti-tumour agents ${ }^{(11)}$. Moreover, a casecontrol study found that potato consumption had a protective effect on rectal cancer among women, but no associations were found for men and, in addition, no associations between potato consumption and risk of colon cancer was found ${ }^{(18)}$. A prospective study of intake of fibre from different sources and risk of colon cancer found that fibre from potatoes was inversely related to colon cancer among men; however, for women the intake of potato fibre was associated with higher risk ${ }^{(19)}$. In addition, two case-control studies found potato consumption to be associated with decreased risk of bladder cancer ${ }^{(20,21)}$. Potatoes have a high glycaemic index (GI) and glycaemic load $(G L)^{(22-24)}$. Even though two earlier meta-analyses concluded that there was no association between GI/GL and pancreatic cancer $^{(25,26)}$, recent studies have found the opposite ${ }^{(27,28)}$. Potatoes are usually eaten as part of a meal ${ }^{(9)}$; therefore, the effect potatoes have on disease risk alone is difficult to determine. A typical Western dietary pattern with high consumption of red and processed meat, potato chips, high fat, dairy products and eggs has been associated with a higher risk of pancreatic cancer among men ${ }^{(29,30)}$, although there are other studies in which this association has not been found ${ }^{(31)}$. Preparation methods of potatoes vary highly across the world, and this is relevant to consider when studying potato consumption and risk of disease. Boiling is assumed to be the healthiest way of preparing, as frying and roasting adds other components, such as fats and salt, to the meal. Acrylamide formation may also be a problem when potatoes are cooked at high temperatures ${ }^{(22,23)}$. However, in the Scandinavian countries, boiling is the most common preparation method ${ }^{(32-34)}$. Information from 24-h dietary recalls performed as part of the European Prospective Investigation into Cancer and Nutrition (EPIC) study showed that boiling was preferred in $70-88 \%$ (standard error of the estimates for Norway, Sweden and Denmark: 0.01) of the meals containing potatoes in the Danish, Swedish and Norwegian populations used for the current study ${ }^{(14)}$. To our knowledge, no prospective study has investigated the association between potatoes as a single food, rather than potatoes being part of a dietary pattern, and the risk of pancreatic cancer. The aim of the present study was to investigate the associations between potato consumption and the risk of pancreatic cancer in a prospective cohort of women and men in the Scandinavian countries.

\section{Methods}

\section{The HELGA study}

The HELGA Study is a large population-based Scandinavian cohort consisting of 119978 participants from The Norwegian Women and Cancer study ${ }^{(35)}$, the Northern Sweden Health and Disease Study Cohort ${ }^{(36)}$ and the Danish Diet, Cancer and Health Study ${ }^{(37)}$. The three cohorts are also part of the EPIC study ${ }^{(38)}$. Data collection was carried out in 1998-1999 (Norway), 1992-1996 (Sweden) and in 1993-1997 (Denmark). In the Norwegian cohort, women aged 40-55 years, from all over Norway, were selected randomly and invited to participate. In the Swedish cohort, the participants consisted of men and women, aged 30, 40, 50 or 60 years, who all were invited to attend a general health screening within the northern county of Västerbotten. The Danish participants were inhabitants in the Copenhagen and Aarhus areas, aged 50-64 years, free of cancer and born in the country who were invited to participate in the Diet, Cancer, and Health study. The participants provided informed consent, and medical ethics review boards in each of the three countries approved the studies.

\section{Dietary assessment}

Semi-quantitative FFQ, filled in at baseline, were used for dietary assessment. The country-specific FFQ reflected the habitual diet during the previous year, and they have all been validated and described in detail elsewhere ${ }^{(39-41)}$. The Norwegian FFQ consisted of eighty-five frequency questions, the Danish consisted of 192 frequency questions and the Swedish consisted of eighty-four frequency questions. The questions on potato consumption varied between the three countries. In Norway, the participants were asked one general question on how many potatoes they ate (never/seldom, 1-4/week, 5-6/ week, $1 / \mathrm{d}, 2 / \mathrm{d}, 3 / \mathrm{d}$ or $4+/ \mathrm{d}$ ). No questions on preparation method were asked. In Denmark, the questionnaire contained seven different questions, where the participants chose which preparation method (boiled, baked, roasted, mashed, stewed, potato salad or French fries) they had used, and they were asked how many times during a specific period of time they ate potatoes prepared in these various ways: never, during a month ( $<1,1,2-3$ times), per week (1, 2-4, 5-6 times) or per day (1, 2-3, 4-5, 6-7, 8+ times). For boiled and baked potatoes, the portion size was specified as one potato, and the participants were asked how many times during a specific period of time they ate one boiled or baked potato (e.g. 1 potato 5-6 times/ week would be 5-6 potatoes/week). In Sweden, the questionnaire contained five questions where the participants chose which preparation method (boiled/baked, roasted, French fries, mashed or potato salad) they had used, and how many times during a specific period of time they ate potatoes prepared in various ways: never, sometimes during a year, per month (1-3 times), per week (1, 2-3, 4-6 times) or per day (1, 2-3, 4+). The amount of food consumed every time was assessed using pictures (a plate with meat, vegetables and potatoes) illustrating four different portion sizes the participants could choose between. In each country, frequencies of all preparation methods were combined with quantities (in $\mathrm{g} / \mathrm{d}$ ) and summed 
into a general variable on potato consumption. Both potatoes as a single food and potato as an ingredient in dishes (pots, soups and hash) were included. The dishes were broken down to the ingredients levels and the ingredients were then added to their respective food groups. As information on preparation methods was unavailable in the Norwegian cohort, and variables for specific preparation methods were not available in the standardised data set, we have focused on total potato consumption. On the basis of the high proportion of boiled potatoes consumed in Norway, Sweden and Denmark ${ }^{(14,42)}$, it is likely that the exposure variable in the present study mainly reflects intake of boiled potatoes. The questionnaires also contained questions on lifestyle and health. The weight and height of the Danish and Swedish participants were measured, whereas in Norway this information was self-reported.

\section{Identification of pancreatic cancer cases}

Over $95 \%$ of pancreatic cancers are adenocarcinomas of the exocrine pancreas ${ }^{(5)}$. We included malignant, primary pancreatic cancer of the exocrine pancreas (carcinomas and adenocarcinomas) as defined by the International Classification of Diseases 10th revision as C25 (C25.0-C25.4 and C25.7-C25.9). Information on cancer incidence and vital status was obtained from national cancer registries, and cause of death registries.

\section{Exclusions}

We excluded 2597 participants with prevalent cancer. The preliminary number of pancreatic cancer cases was 268. We excluded 539 participants, including one case, owing to implausible reported daily energy intake (lower than $2500 \mathrm{~kJ}$ for both sexes, and higher than $18000 \mathrm{~kJ}$ for women and $21000 \mathrm{~kJ}$ for men) and another twenty-seven (no cases) owing to implausible potato intake $(>1 \mathrm{~kg} / \mathrm{d})$. As we included only adenocarcinomas from the exocrine pancreas, forty-four pancreatic cancer cases were excluded because they were neuroendocrine pancreatic tumours, lymphoma, carcinoid, malignant cell and malignant tumour. One case was excluded owing to missing information on cancer morphology. Further, we excluded 2494 participants, including one case, owing to missing information on smoking. Finally, thirty-six participants with follow-up time registered as zero were excluded, as they did not contribute to follow-up. Hence, 114240 participants (38766 men and 75474 women) (Norwegian cohort: 33690, Swedish cohort: 24305 and Danish cohort: 56245) were included in the final analyses. Of these, 221 (121 men and 100 women) were diagnosed with pancreatic cancer during follow-up.

\section{Statistical analysis}

Participant characteristics are presented as medians and 5th-95th percentiles and frequency distributions as appropriate. We used Cox proportional hazard models with hazard ratios (HR) and 95\% CI to estimate the association between potato consumption and the risk of pancreatic cancer. Follow-up time was used as the time variable, and the participants were followed up from date of entry into the study until the date of cancer diagnosis, date of death, date of emigration or the end of follow-up (Denmark, 31 December 2007; Sweden and Norway, 31 December 2008). We present one model stratified by sex, and adjusted for age at recruitment, interaction between age and follow-up time and total energy $(\mathrm{kJ})$, and one fully adjusted model, additionally adjusted for BMI, height and smoking (see below for more details). Owing to differences in the question formulation and general differences in procedures and measurements between the three cohorts, all analyses were stratified by country. Variables classified as 'probably' or 'convincingly' associated with risk of pancreatic cancer in the WCRF/AICR ${ }^{(5)}$ were tested as possible confounders or risk factors: BMI (weight in $\mathrm{kg}$ divided by height in $\mathrm{m}$ squared, $<25 \mathrm{~kg} / \mathrm{m}^{2}$ : underweight/normal-weight, $25-29.9 \mathrm{~kg} / \mathrm{m}^{2}$ : overweight, $\geq 30 \mathrm{~kg} / \mathrm{m}^{2}$ : obese) and smoking status (never, former and current). We also made a finer categorisation of smoking, dichotomising former smokers into those who quit $\leq 10$ years ago or $\geq 11$ years ago, and current smokers into those who smoke $1-15$ cigarettes/d or $\geq 16$ cigarettes/d. However, as this categorisation did not have any material effect on the results, we used the more robust adjustment for smoking status in the final models. Greater childhood growth measured as adult attained height and BMI at aged approximately 20 years is also a probable risk factor, and hence we adjusted for height at baseline. All continuous variables (potato consumption, total energy and height) were tested for linear associations with the outcome. Potato consumption was divided into quartiles in order to fully cover the non-linearity in pancreatic cancer risk, whereas total energy intake was applied in tertiles. Additional variables associated with potato consumption in the Norwegian cohort $^{(42)}$ were assessed for confounding effects: red and processed meat, vegetables, education and diabetes (selfreported). In addition, we did separate analyses by sex. As the number of cases was relatively small, stratification by diabetes was not possible, but in addition to adjust for diabetes we performed sensitivity analyses excluding diabetics. Owing to the small number of cases, we did not perform separate analyses by country, but we repeated all analyses in the Danish cohort only, as this was the largest sub-cohort containing most of the cases. In addition, we performed analyses adjusting for preparation methods in the Danish cohort. We also tested a multivariable adjusted model additionally including dietary factors (red and processed meat, alcohol, carbonated/soft/ isotonic drinks and diluted syrups, and fat) that are characteristic of an obesogenic environment and the metabolic syndrome $^{(43,44)}$ (results not shown). As these variables did not materially change the risk estimates, they were not included in the final models. Adjustment for GI was not done, as these estimates were not available from the food composition database, but we constructed a model (data not shown) where we adjusted for intake of pasta and rice to rule out associations with other main sources of dietary carbohydrate used at dinner meals. Variables were included in the final models if they were significantly associated with pancreatic cancer, or if they influenced the HR by more than $10 \%$. We also adjusted for total energy intake, as this adjustment is usually appropriate to control for confounding in studies on disease and diet. In addition, as our study consisted of three sub-cohorts in different 
countries, this adjustment attenuated possible differences in the information obtained from the FFQ. Tests for trend were performed for all regression analyses, and quartile medians of potato consumption were used in the tests. We performed sensitivity analyses that excluded participants with a pancreatic cancer diagnosis $<1$ year ( $n$ 12) and 3 years ( $n$ 34) after having completed the questionnaire, owing to the possibility that preclinical symptoms affected eating habits. Proportional hazard (PH) assumptions were checked using Schoenfeld residuals, which showed sign of deviation from proportionality. By including an interaction term between age at entry and follow-up time in the models, the $\mathrm{PH}$ assumption was fulfilled for all variables. A $\chi^{2}$ test was performed to check for heterogeneity between sexes. A restricted cubic spline regression model with four knots at fixed percentiles $(5,35,65$ and 95, as suggested by Harrell ${ }^{(45)}$ ) was used to further explore dose-response effects between potato consumption and risk of pancreatic cancer. All variables were checked for multi-collinearity using variance inflation factor, and the results showed no violation of this assumption. Data were analysed using STATA version 14. Calculations showed that the sample size and number of incident pancreatic cancer cases in the HELGA study were sufficiently large to detect a HR of 1.5 for the highest quartile of potato intake compared with the lowest, with a statistical power of $85 \%$ and significance level of $5 \%$.

\section{Results}

The mean follow-up time was 11.4 (95\% CI $0 \cdot 3,16 \cdot 9)$ years. Median age of participants in the quartiles of potato consumption was 52-53 years (Table 1). The cohort consisted of more women than men (66.1\% females) (data not shown), whereas slightly more cases were men $(54 \cdot 8 \%)$. The Swedish sub-cohort had the longest follow-up (mean: 13.3 years), whereas the Danish sub-cohort was the largest ( $49 \%$ of the participants), provided most of the cases (68.8\%) and had, on average, the oldest participants (results not shown in table).

Participants in the highest quartiles of potato consumption tended to be lower educated, taller and to consume more processed meat, fat and total energy (Table 1). Consumption of red meat and alcohol were noticeably lowest in the lowest quartile, and consumption of carbonated/soft/isotonic drinks and diluted syrups was highest in the lowest and highest quartile. In addition, potato consumption was highest in the Swedish participants, and among men. Smoking showed only minor differences across the quartiles of potato consumption. Minor differences were also seen for intake of vegetables, fruits, pasta and rice. Owing to the small differences between the adjusted models (Table 2), we only present HR and CI from the adjusted model 2. Higher consumption of potatoes showed tendencies of higher risk of pancreatic cancer (HR 1.44; $95 \% \mathrm{CI}$ $\left.0.93,2 \cdot 22, P_{\text {for trend }} 0.03\right)$ when comparing the highest $v$, the lowest quartile of consumption in the multivariable model (Table 2). However, compared with the second quartile, both upper quartiles showed a significantly increased risk (data not shown). In the sex-specific analyses, higher consumption was associated with a higher risk of pancreatic cancer for females (HR 2.00; 95\% CI 1.07, 3.72, $P_{\text {for trend }} 0.02$ ). No significant associations were found for men (HR 1.01; $95 \%$ CI 0.56, 1.84). Results from the spline regression models confirmed the absence of dose-response effects between potato consumption and risk of pancreatic cancer (Fig. 1). In sensitivity analyses, excluding participants diagnosed with pancreatic cancer $<1$ (twelve cases) or 3 years (thirty-four cases) after completing the questionnaire did not influence the results. Analysis with a finer categorisation of smoking (including intensity and time since quitting) also did not alter the conclusions. Excluding participants with diabetes (twenty-two cases) did not influence the results. When we repeated all analyses in the Danish cohort (152 cases) only, the overall results were the same (data not shown). Repeating the sex-specific analysis or excluding participants with diabetes in the Danish cohort was not possible owing to the small number of cases.

\section{Discussion}

In this study, we found that participants reporting higher consumption of potatoes showed tendencies at higher risk of pancreatic cancer. In the sex-specific analyses, we found that higher consumption of potatoes was associated with a higher risk of pancreatic cancer for women only. When we further explored the associations by spline regression, the absence of dose-response effects was confirmed. The strengths of this study include its prospective design, which minimises the influence of recall bias. In addition, the high consumption of particularly boiled potatoes in these countries gave us an opportunity to study a population with high potato consumption, where it is not likely that, for example, acrylamide or fat will influence the results. Nevertheless, potatoes are not eaten isolated, but as part of a meal. Further, owing to the use of cancer registries and population registries in the Scandinavian countries, the case coverage was excellent and loss to follow-up was minimal. Another strength of the study is that we, in addition to using standard Cox proportional hazard models, repeated all analyses with spline regression to further explore a possible dose-response effect between high potato consumption and pancreatic cancer risk. It has been discussed that there are other regression methods that could be better suited for analysis than the standard categorical analysis we used at first ${ }^{(46)}$, and one of them is spline regression as standard categorical analysis does not make efficient use of within-category information. As the standard categorical analysis showed relatively inconsistent and non-linear results, with high potato consumption being associated with higher risk of pancreatic cancer in some subgroups, it was important to explore this further. As the results from the spline regression supported the results from the Cox regression, and there was no apparent biological evidence to support the results, we cannot, on the basis of our results, conclude that there is an association between potato consumption and pancreatic cancer. One limitation of the study was that even though the study had a large sample size, the number of cases was relatively small, as expected with a relatively rare cancer type. This restricted our possibility to perform subgroup and stratified analyses, as this affected the statistical power. We tried solving this by, for 
Table 1. Demographic, lifestyle and dietary characteristics by potato consumption in the HELGA cohort (Medians and ranges and 5th-95th percentiles)

\begin{tabular}{|c|c|c|c|c|c|c|c|c|}
\hline \multirow[b]{2}{*}{ Characteristics } & \multicolumn{2}{|c|}{$\begin{array}{l}\text { 1st quartile } \\
(0-73.3 \mathrm{~g})\end{array}$} & \multicolumn{2}{|c|}{$\begin{array}{l}\text { 2nd quartile } \\
(73 \cdot 3-126 \cdot 3 \mathrm{~g})\end{array}$} & \multicolumn{2}{|c|}{$\begin{array}{c}\text { 3rd quartile } \\
(126 \cdot 3-185.9 \mathrm{~g})\end{array}$} & \multicolumn{2}{|c|}{$\begin{array}{c}\text { 4th quartile } \\
(185.9-999.5 \mathrm{~g})\end{array}$} \\
\hline & Median & $\begin{array}{l}\text { 5th-95th } \\
\text { percentile }\end{array}$ & Median & $\begin{array}{l}\text { 5th-95th } \\
\text { percentile }\end{array}$ & Median & $\begin{array}{l}\text { 5th-95th } \\
\text { percentile }\end{array}$ & Median & $\begin{array}{l}\text { 5th-95th } \\
\text { percentile }\end{array}$ \\
\hline$n$ & \multicolumn{2}{|c|}{28103} & \multicolumn{2}{|r|}{28800} & \multicolumn{2}{|c|}{28748} & \multicolumn{2}{|c|}{28589} \\
\hline Cases of pancreatic cancer & \multicolumn{2}{|r|}{35} & \multicolumn{2}{|r|}{43} & \multicolumn{2}{|r|}{67} & \multicolumn{2}{|r|}{76} \\
\hline \multicolumn{9}{|l|}{ Age at recruitment } \\
\hline Median & \multirow{2}{*}{\multicolumn{2}{|c|}{$\begin{array}{c}51 \cdot 0 \\
40 \cdot 3-61 \cdot 7\end{array}$}} & \multicolumn{2}{|r|}{53.0} & \multicolumn{2}{|r|}{$52 \cdot 8$} & \multicolumn{2}{|r|}{$52 \cdot 7$} \\
\hline Range & & & \multicolumn{2}{|c|}{$40 \cdot 0-63 \cdot 3$} & \multirow{2}{*}{\multicolumn{2}{|c|}{$39 \cdot 9-63.5$}} & \multicolumn{2}{|c|}{$30 \cdot 6-63 \cdot 6$} \\
\hline \multicolumn{5}{|l|}{$\operatorname{Sex}(\%)$} & & & & \\
\hline Men & \multirow{2}{*}{\multicolumn{2}{|c|}{$\begin{array}{l}16 \cdot 9 \\
83 \cdot 1\end{array}$}} & \multicolumn{2}{|r|}{$29 \cdot 7$} & & $36 \cdot 5$ & & $52 \cdot 3$ \\
\hline Women & & & & $70 \cdot 3$ & & 63.5 & & $47 \cdot 7$ \\
\hline Country (\%) & & & & & & & & \\
\hline Denmark & & 34.9 & & $58 \cdot 3$ & & $53 \cdot 3$ & & $50 \cdot 1$ \\
\hline Sweden & & $12 \cdot 9$ & & $17 \cdot 8$ & & $22 \cdot 2$ & & $32 \cdot 0$ \\
\hline Norway & & $52 \cdot 2$ & & 23.9 & & 24.5 & & $17 \cdot 9$ \\
\hline Smoking status & & & & & & & & \\
\hline Never & & 39.2 & & $42 \cdot 8$ & & $41 \cdot 2$ & & $39 \cdot 1$ \\
\hline Former & & $30 \cdot 0$ & & $28 \cdot 0$ & & $28 \cdot 1$ & & $27 \cdot 6$ \\
\hline Current & & $30 \cdot 8$ & & $29 \cdot 2$ & & $30 \cdot 7$ & & $33 \cdot 3$ \\
\hline $\begin{array}{l}\text { Highest level of education complete } \\
(\%)\end{array}$ & & & & & & & & \\
\hline None/primary school & & $22 \cdot 8$ & & $27 \cdot 4$ & & $30 \cdot 3$ & & $35 \cdot 6$ \\
\hline Technical/professional school & & 34.9 & & $36 \cdot 9$ & & $34 \cdot 1$ & & $30 \cdot 6$ \\
\hline Secondary school & & 24.4 & & $18 \cdot 3$ & & $17 \cdot 9$ & & $16 \cdot 8$ \\
\hline $\begin{array}{l}\text { Higher education (including } \\
\text { university) }\end{array}$ & & $17 \cdot 9$ & & $17 \cdot 4$ & & $17 \cdot 7$ & & $17 \cdot 0$ \\
\hline Diabetes (\%) & & & & & & & & \\
\hline Diabetics & & $1 \cdot 8$ & & $1 \cdot 7$ & & 1.7 & & 1.8 \\
\hline Non-diabetics & & $96 \cdot 7$ & & $95 \cdot 8$ & & $96 \cdot 0$ & & $95 \cdot 7$ \\
\hline Unknown & & 1.6 & & 2.5 & & $2 \cdot 2$ & & $2 \cdot 5$ \\
\hline $\operatorname{BMI}\left(\mathrm{kg} / \mathrm{m}^{2}\right)$ & $24 \cdot 3$ & $19 \cdot 7-32 \cdot 3$ & $24 \cdot 8$ & $20 \cdot 0-32 \cdot 7$ & 24.9 & $20 \cdot 0-32 \cdot 6$ & $25 \cdot 0$ & $20 \cdot 0-32 \cdot 7$ \\
\hline Height $(\mathrm{cm})$ & 167 & $157-181$ & 168 & $156-183$ & 169 & $157-184$ & 171 & $158-186$ \\
\hline Consumption & & & & & & & & \\
\hline Vegetables $(\mathrm{g} / \mathrm{d})$ & 122 & $25-309$ & 133 & 28-335 & 139 & $30-340$ & 127 & $25-343$ \\
\hline Fruits $(g / d)$ & 133 & $17-425$ & 137 & $22-433$ & 141 & $23-433$ & 131 & $20-433$ \\
\hline Red meat $(\mathrm{g} / \mathrm{d})$ & 25 & $4-119$ & 42 & $6-119$ & 43 & $7-130$ & 43 & $8-145$ \\
\hline Processed meat $(\mathrm{g} / \mathrm{d})$ & 25 & $4-73$ & 25 & $6-68$ & 30 & $7-76$ & 37 & 9-94 \\
\hline Pasta (g/d) & 19 & $0-79$ & 19 & $1-84$ & 18 & $0-84$ & 16 & $0-84$ \\
\hline Rice (g/d) & 16 & $0-64$ & 16 & $1-64$ & 16 & $1-75$ & 14 & $1-75$ \\
\hline $\begin{array}{l}\text { Carbonated/soft/isotonic drinks, } \\
\text { diluted syrups(g/d) }\end{array}$ & 39 & $0-454$ & 29 & $0-500$ & 33 & $0-500$ & 39 & $0-507$ \\
\hline Alcohol $(g / d)$ & $2 \cdot 6$ & $0-37 \cdot 3$ & $6 \cdot 0$ & $0-46 \cdot 2$ & $5 \cdot 3$ & $0-50 \cdot 3$ & $5 \cdot 3$ & $0-56.4$ \\
\hline Total fats $(\mathrm{g} / \mathrm{d})$ & 58 & $31-104$ & 67 & $36-117$ & 73 & $40-127$ & 82 & $44-146$ \\
\hline Total energy $(\mathrm{kJ} / \mathrm{d})$ & 6666 & $3912-10709$ & 7611 & $4616-12060$ & 8288 & $5037-13058$ & 9332 & 5674-14 912 \\
\hline
\end{tabular}

instance, excluding those with diabetes instead of performing separate analysis on diabetics. The results remained unchanged. Adjustments for diabetes did not have any material effect on the results either. We applied a finer categorisation for smoking status, which did not have any effect on the results. Nevertheless, the study will probably suffer from some residual confounding. Our results were based on data from selfadministered questionnaires, which is a potential source of measurement error. However, the food data were standardised by common standardisation guidelines. The questions on potato consumption varied across the three countries, and the questionnaire in the Norwegian cohort did not have any questions on preparation method. Therefore, total potato consumption was summed up into a general variable in $\mathrm{g} / \mathrm{d}$. Ideally, questions on preparation method should have been included; however, information from 24-h dietary recalls performed as part of the EPIC study showed that boiling was the most common preparation method in meals containing potatoes in the Danish, Swedish and Norwegian populations included in the current study ${ }^{(14)}$. Adjustment for GI was not done, as these estimates were not available from the food composition database. In addition, information on $H$. pylori, insulin resistance and chronic pancreatitis, which have been associated with pancreatic cancer, was not available. In addition, it is important to keep in mind that the results of the present study were based on only one measurement, and dietary changes could have occurred during the follow-up period. As potatoes are usually eaten as part of a meal, it is also important to keep in mind that the effect potatoes have on disease risk alone is difficult to determine. Foods that are part of a meal interact with other dietary components and nutrients, and thus the impact of potato consumption on disease risk may depend on which other foods they are grouped with in a dietary pattern $^{(9)}$. These issues are also present regarding GI, as the 
Table 2. Risk* for pancreatic cancer according to potato consumption in the HELGA study ( $n$ 114240)

(Hazard ratios and $95 \%$ confidence intervals)

\begin{tabular}{|c|c|c|c|c|c|}
\hline \multirow[b]{2}{*}{ Potatoes (g/d) } & \multirow[b]{2}{*}{ Cases } & \multicolumn{2}{|c|}{ Adjusted model $1 \dagger$} & \multicolumn{2}{|c|}{ Adjusted model $2 \ddagger$} \\
\hline & & $\mathrm{HR}$ & $95 \% \mathrm{Cl}$ & $\mathrm{HR}$ & $95 \% \mathrm{Cl}$ \\
\hline \multicolumn{6}{|l|}{ Both sexes } \\
\hline Q1 & 35 & & Ref. & & Ref. \\
\hline Q2 & 43 & 0.87 & $0.55,1.38$ & 0.87 & $0.55,1.38$ \\
\hline Q3 & 67 & 1.33 & $0.87,2.05$ & 1.32 & $0.86,2.03$ \\
\hline Q4 & 76 & 1.45 & $0.94,2.25$ & 1.44 & $0.93,2.22$ \\
\hline$P \S$ & & & $0.026 \|$ & & $0.030 \|$ \\
\hline \multicolumn{6}{|l|}{ Females ( $n 75474)$} \\
\hline Q1: $0-73.3$ & 16 & & Ref. & & Ref. \\
\hline Q2: $73 \cdot 3-126 \cdot 2$ & 17 & $1 \cdot 14$ & $0 \cdot 61,2 \cdot 11$ & $1 \cdot 15$ & $0.62,2 \cdot 12$ \\
\hline Q3: $126 \cdot 3-185 \cdot 9$ & 39 & 1.51 & $0.82,2.77$ & 1.49 & $0.81,2.73$ \\
\hline Q4: $185 \cdot 9-910 \cdot 2$ & 49 & $2.05 \|$ & $1 \cdot 10,3 \cdot 81 \|$ & $2 \cdot 00 \|$ & $1.07,3.72 \|$ \\
\hline$P \S$ & & & $0.016 \|$ & & $0.020 \|$ \\
\hline \multicolumn{6}{|l|}{ Males ( $n 38766)$} \\
\hline Q1: $0-73.3$ & 19 & & Ref. & & Ref. \\
\hline Q2: $73 \cdot 3-126 \cdot 3$ & 26 & 0.58 & $0.29,1.17$ & 0.58 & $0.29,1.17$ \\
\hline Q3: $126 \cdot 3-185 \cdot 9$ & 28 & 1.06 & $0.58,1.94$ & 1.06 & $0.58,1.94$ \\
\hline Q4: 185.9-999.5 & 27 & 1.01 & $0.56,1.84$ & 1.01 & $0.56,1.84$ \\
\hline$P \S$ & & & 0.349 & & 0.344 \\
\hline
\end{tabular}

$Q$, quartile; Ref., referent values.

* As estimated by Cox proportional hazards regression.

$\dagger$ Stratified by country and sex, and adjusted for age at recruitment, interaction between age and time, and total energy $(\mathrm{kJ})$.

‡ Additionally adjusted for BMI, height and smoking

$\S$ Test for trend, based on median potato consumption in each quartile.

॥ Values are significant.

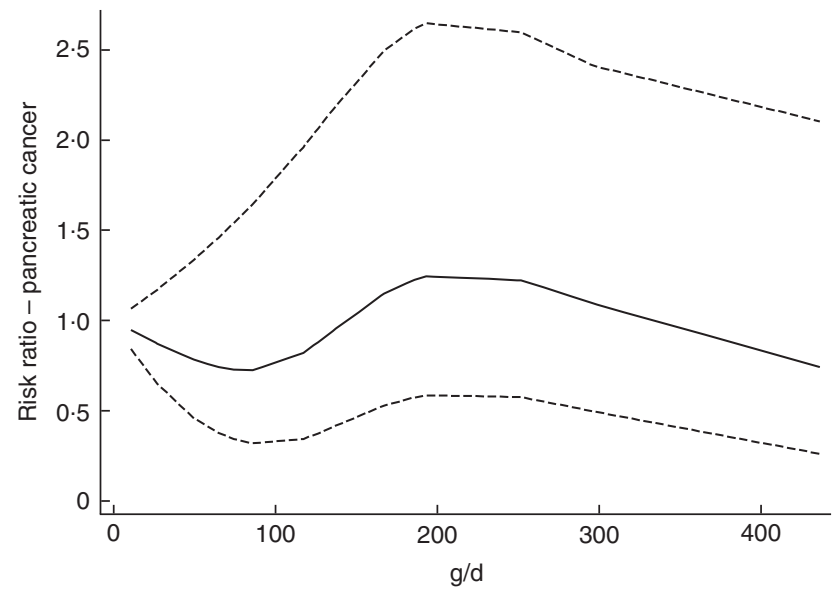

Fig. 1. Association between potato consumption (per $100 \mathrm{~g} / \mathrm{d}$ ) and pancreatic cancer risk. As estimated by a restricted cubic Spline regression model with four knots at fixed percentiles $\left(5,35,65,95\right.$, suggested by Harrell $\left.{ }^{(45)}\right)$. Adjusted for sex, total energy $(\mathrm{kJ})$, BMI, height, smoking status and stratified by country.

postprandial glycaemic response is influenced by several factors in a meal, such as the source and amount of carbohydrates and the type and amount of fibre present ${ }^{(9)}$. In addition, the ingredients or other foods eaten together with potatoes will influence the GI and the postprandial glycaemic response. The variety of potatoes and the preparation method will also play a part $^{(9)}$. The research on pancreatic cancer and GI is inconsistent; two earlier meta-analyses concluded that there was no association $^{(25,26)}$, whereas two recent studies found that diets with high GI and GL increased the risk of pancreatic cancer $^{(27,28)}$. As mentioned, adjustment for GI was not possible in the present study, but we constructed a model (data not shown) where we adjusted for intake of pasta and rice to rule out associations with other main sources of dietary carbohydrate used at dinner meals, and the results were still the same. Adjusting for preparation methods (boiled, baked, fried, roasted, mashed, potato salad and stewed) in the Danish cohort did not change the original results (results not shown). Participants in the highest quartile of potato consumption showed some characteristics that are known to be associated with pancreatic cancer, like they tended to have a higher BMI. The participants in the highest quartile were also slightly taller. Regarding dietary factors, they consumed more processed meat, and had a generally higher intake of total fat and total daily energy intake. The evidence regarding these dietary factors in association with pancreatic cancer is limited ${ }^{(5)}$; however, these factors are characteristics of an obesogenic environment and the metabolic syndrome ${ }^{(43,44)}$. The metabolic syndrome is a cluster of risk factors related to risk for stroke, heart disease, diabetes type 2, overweight, obesity and insulin resistance ${ }^{(43)}$, and the incidence of this syndrome increases with age ${ }^{(47)}$. However, multivariable adjusted models including these variables did not materially change the risk estimated, and they were not included in the final models. The main reason for not including them was the limited number of pancreatic cancer cases in our study sample, and we aimed to retain power in our statistical analyses. The metabolic syndrome has become more common owing to increasing obesity rates among adults ${ }^{(43)}$. In addition, several studies have found the metabolic syndrome to be associated with a higher risk of pancreatic cancer ${ }^{(48,49)}$. The key component of the metabolic syndrome in pancreatic carcinogenesis was suggested to be diabetes ${ }^{(49)}$. As mentioned, exclusion of participants with diabetes (twenty-two cases) did not influence the results in the present study. Even though there is a lack of research regarding long-term cancer-related health effects of potatoes $^{(11)}$, there are several studies that have found an association between potato consumption and cancer: in particular, one case-control study found that a high potato consumption was associated with a higher risk of pancreatic cancer ${ }^{(12)}$. It is also interesting that some studies on dietary patterns, rather than studies on potatoes per se, show that a western dietary pattern that includes potatoes has been associated with a higher risk of pancreatic cancer among men ${ }^{(29,30)}$. However, these findings are not consistent ${ }^{(31)}$. In addition, some studies have found potato consumption to be associated with a higher risk of other cancers of the digestive system, such as rectal cancer ${ }^{(16)}$, colon cancer (tendencies) ${ }^{(13)}$ and colorectal cancer ${ }^{(14)}$. Other studies have shown contradictory or inconclusive results regarding gastric, colon and rectal cancer ${ }^{(15,18,19)}$.

\section{Conclusion}

In this study, we cannot conclude that there is an association between potato consumption and risk of pancreatic cancer. However, potatoes are a staple food in many countries, and there are generally few and inconsistent studies within this field. In addition, the inconsistent findings in the present study emphasise the need for more and larger studies investigating 
the association between potato consumption and pancreatic cancer, and potatoes and health in general.

\section{Acknowledgements}

The authors thank Katja Boll for assistance with data preparation. In addition, the authors thank pathologist Lill Tove Busund for assisting with cancer information.

This work was supported by the Norwegian ExtraFoundation for Health and Rehabilitation through EXTRA funds. The Norwegian ExtraFoundation for Health and Rehabilitation had no role in the design, analysis or writing of this article.

L. A. A., G. S., A. O., E. L. and T. B. designed the research; L. A. A. analysed data and wrote the paper; T. B. supervised the statistical analyses, performed supporting analyses, commented on the manuscript and has contributed in organising data in the Norwegian Women and Cancer Study; A. O. supervised and commented on the analyses and the manuscript and has contributed in organising data in the Danish Diet, Cancer and Health Study; E. L., Principal Investigator of NOWAC, and A. T., K. O., L. M. N. and F. R. contributed in designing the local cohort studies and commented on the manuscript; G. S. supervised the statistical analyses, commented and supervised the drafting of the manuscript and has contributed in organising data in the Norwegian Women and Cancer Study. All authors read and approved the final manuscript.

None of the authors has any conflicts of interest to declare.

\section{References}

1. Ferlay J, Shin H-R, Bray F, et al. (2010) Estimates of worldwide burden of cancer in 2008: GLOBOCAN 2008. Int J Cancer 127, 2893-2917.

2. Center MM, Jemal A \& Ward E (2009) International trends in colorectal cancer incidence rates. Cancer Epidemiol Biomarkers Prev 18, 1688-1694.

3. Parkin DM (2004) International variation. Oncogene 23 6329-6340.

4. Yeo TP \& Lowenfels AB (2012) Demographics and epidemiology of pancreatic cancer. Cancer J 18, 477-484.

5. World Cancer Research Fund/American Institute for Cancer Research (2012) Continous update project report. Food, nutrition, physical activity, and the prevention of pancreatic cancer. http://www.dietandcancerreport.org (accessed June 2016).

6. American Cancer Society (2016) Learn about cancer. Pancreatic cancer risk faktors. http://www.cancer.org/cancer/pancreatic cancer/detailedguide/pancreatic-cancer-risk-factors (accessed June 2016).

7. Zaheer K \& Akhtar MH (2016) Potato production, usage, and nutrition - a review. Crit Rev Food Sci Nutr 56, 711-721.

8. Totland TH, Melnes BK, Lundberg-Hallèn N, et al. (2012) Norkost 3. En landsomfattende kostholdsundersøkelse blant menn og kvinner $i$ Norge $i$ alderen 18-70 år, 2010-11 (Nationwide Dietary Survey in Norway Among Men and Women Aged 18-70 years, 2010-11). Oslo: University of Oslo, Norwegian Food Safety Authority, Norwegian Directorate of Health.

9. McGill CR, Kurilich AC \& Davignon J (2013) The role of potatoes and potato components in cardiometabolic health: a review. Ann Med 45, 467-473.
10. Hagen ML (2016) Poteter og livsstilssykdommer. En systematisk oversiktsartikkel (Potatoes and diseases of affluence. A systematic review). NTFE 2, 6-12.

11. Camire ME, Kubow S \& Donnelly DJ (2009) Potatoes and human health. Crit Rev Food Sci Nutr 49, 823-840.

12. Polesel J, Talamini R, Negri E, et al. (2010) Dietary habits and risk of pancreatic cancer: an Italian case-control study. Cancer Causes Control 21, 493-500.

13. Steinmetz KA \& Potter JD (1993) Food-group consumption and colon cancer in the Adelaide Case-Control Study. I. Vegetables and fruit. Int J Cancer 53, 711-719.

14. Åsli LA, Olsen A, Braaten T, et al. (2017) Potato consumption and risk of colorectal cancer in the Norwegian women and cancer cohort. Nutr Cancer 69, 564-572.

15. De Stefani E, Correa P, Boffetta P, et al. (2004) Dietary patterns and risk of gastric cancer: a case-control study in Uruguay. Gastric Cancer 7, 211-220.

16. Williams CD, Satia JA, Adair LS, et al. (2009) Dietary patterns, food groups, and rectal cancer risk in Whites and African Americans. Cancer Epidemiol Biomarkers Prev 18, 1552-1561.

17. Bravi F, Bosetti C, Filomeno M, et al. (2013) Foods, nutrients and the risk of oral and pharyngeal cancer. Br J Cancer $\mathbf{1 0 9}$, 2904-2910.

18. Deneo-Pellegrini H, Boffetta P, De Stefani E, et al. (2002) Plant foods and differences between colon and rectal cancers. Eur J Cancer Prev 11, 369-375.

19. Hansen L, Skeie G, Landberg R, et al. (2012) Intake of dietary fiber, especially from cereal foods, is associated with lower incidence of colon cancer in the HELGA cohort. Int J Cancer 131, 469-478.

20. Balbi JC, Larrinaga MT, De Stefani E, et al. (2001) Foods and risk of bladder cancer: a case-control study in Uruguay. Eur J Cancer Prev 10, 453-458.

21. Isa F, Xie L-P, Hu Z, et al. (2013) Dietary consumption and diet diversity and risk of developing bladder cancer: results from the South and East China case-control study. Cancer Causes Control 24, 885-895.

22. Ludwig DS (2002) The glycemic index: physiological mechanisms relating to obesity, diabetes, and cardiovascular disease. JAMA 287, 2414-2423.

23. van Bakel MME, Kaaks R, Feskens EJM, et al. (2009) Dietary glycaemic index and glycaemic load in the European Prospective Investigation into Cancer and Nutrition. Eur J Clin Nutr 63, S188-S205.

24. Wirfält E, McTaggart A, Pala V, et al. (2007) Food sources of carbohydrates in a European cohort of adults. Public Health Nutr 5, 1197-1215.

25. Aune D, Chan DSM, Vieira AR, et al. (2012) Dietary fructose, carbohydrates, glycemic indices and pancreatic cancer risk: a systematic review and meta-analysis of cohort studies. Ann Oncol 23, 2536-2546.

26. Choi Y, Giovannucci E \& Lee JE (2012) Glycaemic index and glycaemic load in relation to risk of diabetes-related cancers: a meta-analysis. Br J Nutr 108, 1934-1947.

27. Hu J, La Vecchia C, Augustin LS, et al. (2013) Glycemic index, glycemic load and cancer risk. Ann Oncol 24, 245-251.

28. Turati F, Galeone C, Gandini S, et al. (2015) High glycemic index and glycemic load are associated with moderately increased cancer risk. Mol Nutr Food Res 59, 1384-1394.

29. Bosetti C, Bravi F, Turati F, et al. (2013) Nutrient-based dietary patterns and pancreatic cancer risk. Ann Epidemiol 23, 124-128.

30. Chan JM, Gong Z, Holly EA, et al. (2013) Dietary patterns and risk of pancreatic cancer in a large population-based casecontrol study in the San Francisco Bay Area. Nutr Cancer 65 , $157-164$. 
31. Michaud DS, Skinner HG, Wu K, et al. (2005) Dietary patterns and pancreatic cancer risk in men and women. J Natl Cancer Inst 97, 518-524.

32. Statistiska Centralbyrån (Statistics Sweden) (2002) Potatis konsumtion och fritidsodling (Potatoes - consumption and cultivation). http://www.scb.se/statistik/JO/JO0603/2003M00/ JOFT0201.pdf (accessed March 2016).

33. Nasjonalt råd for ernæring (National Nutrition Council) (2011) Kostråd for å fremme folkehelsen og forebygge kroniske sykdommer. Metodologi og vitenskapelig kunnskapsgrunnlag (Dietary guidelines to promote public health and prevent chronic diseases. Research methods and knowledge base). https://helsedirektoratet.no/Lists/Publikasjoner/Attachments/ 400/Kostrad-for-a-fremme-folkehelsen-og-forebygge-kroniskesykdommer-metodologi-og-vitenskapelig-kunnskapsgrunnlag-IS1881.pdf (accessed March 2016).

34. Danmarks Fødevare- og Veterinærforskning (Danish Institute for Food and Veterinary Research) (2004) Afdeling for Ernæring. Udviklingen i danskernes kost 1985-2001. Med fokus på sukker og alkohol samt motivation (Danish dietary habits 1985-2001. Focusing on sugar and alcohol as well as motivation and barriers for a healthy lifestyle). http://docplayer. dk/17487389-Udviklingen-i-danskernes-kost-1985-2001.html (accessed March 2016).

35. Lund E, Dumeaux V, Braaten T, et al. (2008) Cohort profile: the Norwegian Women and Cancer Study - NOWAC Kvinner og kreft. Int J Epidemiol 37, 36-41.

36. Winkvist A, Hörnell A, Hallmans G, et al. (2009) More distinct food intake patterns among women than men in northern Sweden: a population-based survey. Nutr J 8, 12 .

37. Tjønneland A, Olsen A, Boll K, et al. (2007) Study design, exposure variables, and socioeconomic determinants of participation in Diet, Cancer and Health: a population-based prospective cohort study of 57,053 men and women in Denmark. Scand J Public Health 35, 432-441.

38. Riboli E, Hunt KJ, Slimani N, et al. (2007) European Prospective Investigation into Cancer and Nutrition (EPIC): study populations and data collection. Public Health Nutr 5, 1113-1124.
39. Hjartåker A, Andersen LF \& Lund E (2007) Comparison of diet measures from a food-frequency questionnaire with measures from repeated 24-hour dietary recalls. The Norwegian Women and Cancer Study. Public Health Nutr 10, 1094-1103

40. Johansson I, Hallmans G, Wikman A, et al. (2007) Validation and calibration of food-frequency questionnaire measurements in the Northern Sweden Health and Disease cohort. Public Health Nutr 5, 487-496.

41. Tjønneland A, Overvad K, Haraldsdóttir J, et al. (1991) Validation of a semiquantitative food frequency questionnaire developed in Denmark. Int J Epidemiol 20, 906-912.

42. Åsli LA, Braaten T, Olsen A, et al. (2015) What characterises women who eat potatoes? A cross-sectional study among 74,208 women in the Norwegian Women and Cancer cohort. Food Nutr Res 59, 25703.

43. National Heart, Lung and Blood Institute (2016) What is metabolic syndrome? National Institute of Health. http:// www.nhlbi.nih.gov/health/health-topics/topics/ms (accessed March 2016).

44. Lake A \& Townshend T (2006) Obesogenic environments: exploring the built and food environments. $J$ R Soc Promot Health 126, 262-267.

45. Harrell FE Jr (2001) Regression Modeling Strategies: With Applications to Linear Models, Logistic Regression, and Survival Analysis. New York: Springer.

46. Greenland S (1995) Dose-response and trend analysis in epidemiology: alternatives to categorical analysis. Epidemio$\log \mathbf{6}$, 356-365.

47. Kuk JL \& Ardern CI (2010) Age and sex differences in the clustering of metabolic syndrome factors: association with mortality risk. Diabetes Care 33, 2457-2461.

48. Esposito K, Chiodini P, Colao A, et al. (2012) Metabolic syndrome and risk of cancer: a systematic review and metaanalysis. Diabetes Care 35, 2402-2411.

49. Rosato V, Tavani A, Bosetti C, et al. (2011) Metabolic syndrome and pancreatic cancer risk: a case-control study in Italy and meta-analysis. Metabolism 60, 1372-1378. 